\title{
Taphonomic and ecologic information from bone weathering
}

\author{
Anna K. Behrensmeyer
}

\begin{abstract}
Bones of recent mammals in the Amboseli Basin, southern Kenya, exhibit distinctive weathering characteristics that can be related to the time since death and to the local conditions of temperature, humidity and soil chemistry. A categorization of weathering characteristics into six stages, recognizable on descriptive criteria, provides a basis for investigation of weathering rates and processes. The time necessary to achieve each successive weathering stage has been calibrated using known-age carcasses. Most bones decompose beyond recognition in 10 to 15 yr. Bones of animals under $100 \mathrm{~kg}$ and juveniles appear to weather more rapidly than bones of large animals or adults. Small-scale rather than widespread environmental factors seem to have greatest influence on weathering characteristics and rates. Bone weathering is potentially valuable as evidence for the period of time represented in recent or fossil bone assemblages, including those on archeological sites, and may also be an important tool in censusing populations of animals in modern ecosystems.
\end{abstract}

Anna K. Behrensmeyer. Peabody Museum, Yale University; New Haven, Connecticut 06520

Accepted: January 6, 1978

\section{Introduction}

Vertebrate bones decompose on subaerial surfaces, and their destruction can be viewed as part of the normal process of nutrient recycling in and on soils. Whether or not a bone survives to become fossilized depends on the intensity and rate of various destructive processes and the chance for permanent burial prior to total destruction. Surprisingly little is known about how these processes affect bones, and how they may consequently bias the vertebrate fossil record.

Bones freed of covering tissue and exposed on the ground surface usually undergo rather rapid changes in appearance. Various researchers interested in bone decomposition have conducted small-scale experiments or have collected observations on recent bones which indicate that weathering may follow broadly similar patterns in different environments (Voorhies 1969; Isaac 1967; Brain 1967; Hill 1975, pers. comm.; D. Gifford, pers. comm.; Tappen and Peske 1970). Ecologists have recently become interested in aging vertebrate carcasses using weathering characteristics (D. Western, pers. comm.). However, little systematic work has been done to define types of bone weathering and relate these to specific processes acting over known periods of time.

This paper will present a descriptive categorization of weathering based on systematic observations of recent bones in Amboseli Park, Kenya. Weathering categories or "stages" are set up to provide a basis for descriptive comparison with bones from other contexts, both fossil and recent. Within the Amboseli ecosystem, it is possible to show how the weathering stages relate to rates of decomposition and to surface processes characteristic of different macro- and micro-habitats. Such information provides a basis for assessing the potential value of bone weathering as a source of ecologic and taphonomic data, both within the Amboseli Basin and in a more general context.

\section{Background}

The study of bone weathering grew out of a broader taphonomic sampling program initiated in 1975. The results of the overall study of the recent bone assemblage in the Amboseli Basin will be reported elsewhere (Behrensmeyer and Dechant, in prep.).

The Amboseli Basin lies at the northern edge of Mt. Kilimanjaro in southern Kenya (Fig. 1) 


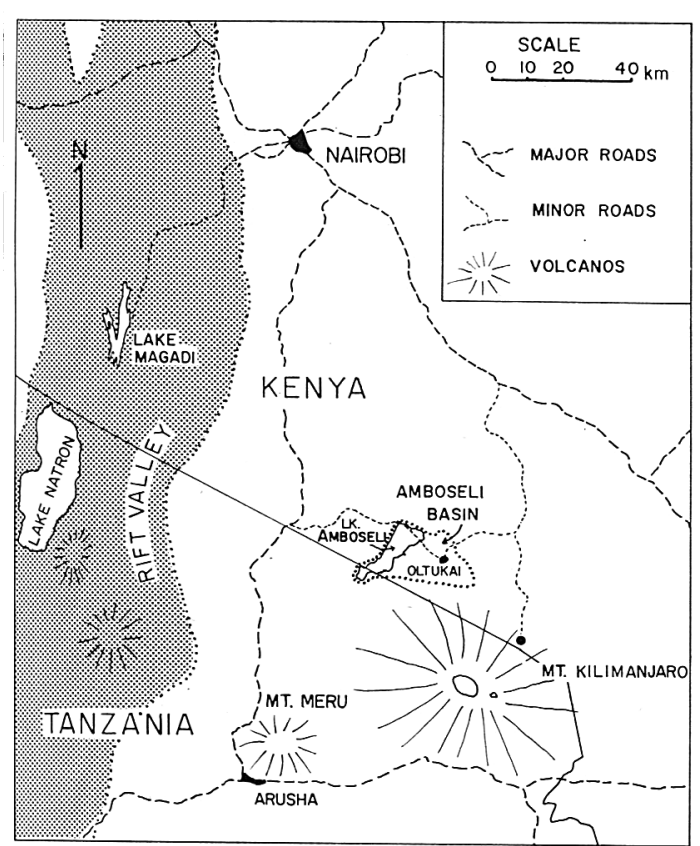

Figure 1. Map showing general location of the Amboseli Basin in southern Kenya. Lake Amboseli is dry except during periods of heavy rainfall.

and includes $600 \mathrm{~km}^{2}$ of flat-lying terrain covered by a mosaic of vegetation zones. The basin is internally drained, and soils are generally alkaline. Amboseli National Park covers a part of the basin area which is used by a diverse fauna of wild herbivores and carnivores, as well as Maasai people, domestic stock, and tourists. Numbers of animals in the park fluctuate seasonally, and highest concentrations occur during dry periods, when the only available water flows from the base of Kilimanjaro (Western and Van Praet 1973).

Sampling of the bone assemblage in the central basin was done using linear transects covering parts of six major habitats. These habitats included swamp, dense woodland, open woodland, plains, bush and lakebed. The lakebed is dry most of the year, with sporadic inundation for 1 to 2 months following periods of heavy rain. Weathering stages defined by easily observable criteria were established early in the sampling program and used throughout the study. Reference bones and photographs were used as standards of comparison. Considerable effort has gone into making the descriptions given below simple and straightforward so that they can be readily learned and applied in the field.

\section{Bone Weathering Stages}

Stage 0.-Bone surface shows no sign of cracking or flaking due to weathering. Usually bone is still greasy, marrow cavities contain tissue, skin and muscle/ligament may cover part or all of the bone surface.

Stage 1.-Bone shows cracking, normally parallel to the fiber structure (e.g., longitudinal in long bones). Articular surfaces may show mosaic cracking of covering tissue as well as in the bone itself. Fat, skin and other tissue may or may not be present. (Fig. 2a)

Stage 2.-Outermost concentric thin layers of bone show flaking, usually associated with cracks, in that the bone edges along the cracks tend to separate and flake first. Long thin flakes, with one or more sides still attached to the bone, are common in the initial part of Stage 2. Deeper and more extensive flaking follows, until most of the outermost bone is gone. Crack edges are usually angular in crosssection. Remnants of ligaments, cartilage, and skin may be present. (Fig. 2b)

Stage 3.-Bone surface is characterized by patches of rough, homogeneously weathered compact bone, resulting in a fibrous texture. In these patches, all the external, concentrically layered bone has been removed. Gradually the patches extend to cover the entire bone surface. Weathering does not penetrate deeper than $1.0-1.5 \mathrm{~mm}$ at this stage, and bone fibers are still firmly attached to each other. Crack edges usually are rounded in cross-section. Tissue rarely present at this stage. (Fig. 2c)

Stage 4.-The bone surface is coarsely fibrous and rough in texture; large and small splinters occur and may be loose enough to fall away from the bone when it is moved. Weathering penetrates into inner cavities. Cracks are open and have splintered or rounded edges. (Fig. 2d)

Stage 5.-Bone is falling apart in situ, with large splinters lying around what remains of the whole, which is fragile and easily broken by moving. Original bone shape may be difficult to determine. Cancellous bone usually exposed, when present, and may outlast all traces of the former more compact, outer parts of the bones. (Fig. 2e)

In deciding what stage to record for a particular bone, the following guidelines are used; 


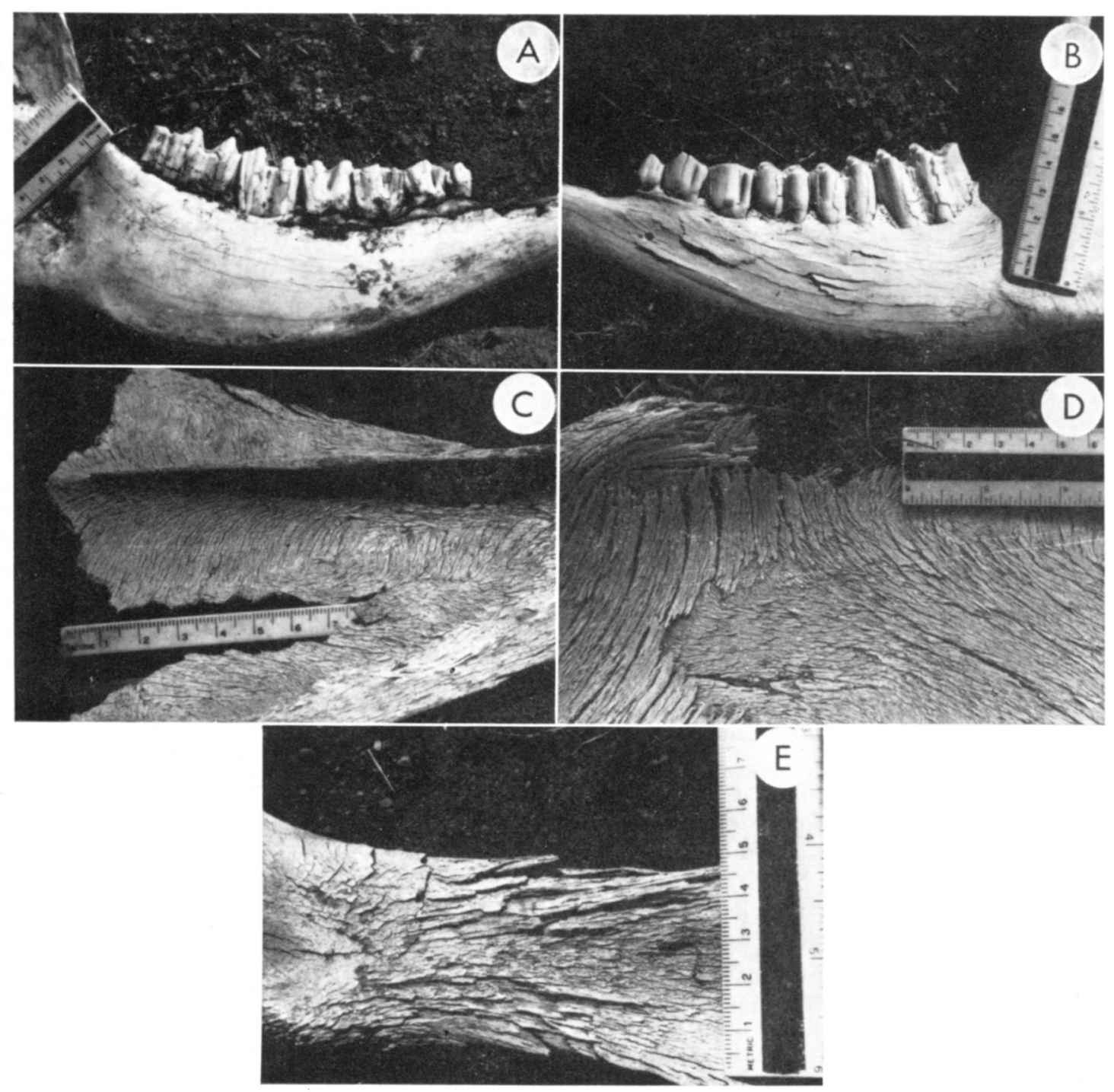

Figure 2. Weathering stages for the Amboseli recent bone assemblage. a: Stage 1: cow mandible showing initial cracking parallel to bone fiber structure; b: Stage 2: opposite side of same cow mandible showing flaking of outer bone layers; c: Stage 3: bovid scapula showing fibrous, rough texture and remnants of surface bone near lower right border; d: Stage 4: part of scapula showing deep cracking, coarse, layered fiber structure; $e$ : Stage 5: scapula blade showing final stages of deep cracking and splitting. ( $15 \mathrm{~cm}$ scale in all photographs)

1) The most advanced stage which covers patches larger than $1 \mathrm{~cm}^{2}$ of the bone's surface is recorded.

2) Whenever possible shafts of limb bones, flat surfaces of jaws, pelves, vertebrae, or ribs are used, not edges of bones or areas where there is evidence of physical damage (e.g., gnawing).

3) All observers must agree concerning the stage before it is recorded.

The larger skeletal parts are easiest to cate- gorize. Small, compact bones such as podials and phalanges weather more slowly than other elements of the same skeleton and do not exhibit all the diagnostic characteristics of the weathering stages. In deciding the stage for a carcass with many parts, rather than for an isolated bone, it is advisable to examine several different bones (e.g., a limb bone, rib, ilium, vertebral spine) to assess the most advanced weathering characteristics.

The six weathering stages impose arbitrary 
divisions upon what was observed to be a continuous spectrum, and this created some problems of categorization. For instance, many bones were equally covered by Stage 2 and Stage 3 surfaces, and proved difficult to place in one or the other category. However, by employing the criterion of "most advanced stage covering more than $1 \mathrm{~cm}^{2}$," most of these problems were resolved. The success of the scheme has been indicated by the ease with which new observers recognize the stages, and there may be some "natural" component in the classification. This could reflect the fact that bones spend relatively longer periods within each stage than between them. However, at this point the stages should be treated as provisional descriptive categories only.

In general the six weathering stages are only applicable to mammals larger than $5 \mathrm{~kg}$ body weight, and a weathering classification has not been attempted for smaller animals. Bones of mammals such as the African hare (Lepus capensis) clearly differ in weathering characteristics from the larger species in Amboseli and seem more subject to cracking and splintering rather than flaking. Bones of birds, reptiles and fish also differ from mammals in weathering features, and each group will eventually require separate study.

In Amboseli the weathering characteristics of teeth could not be related in any consistent way to the bone stages. There are mandibles in Stage 3-4 with uncracked teeth, and Stage 1-2 mandibles with severely fractured teeth. Teeth seem to split easily when subjected to surface desiccation, but the lack of any clear pattern of weathering suggests that the individual characteristics of each tooth, including stage of eruption, wear, ratio of enamel to dentine and overall morphology, may be most important in determining characteristics and rates of weathering. More rapid fragmentation of teeth relative to bone cannot be related simply to arid climate, as suggested by Toots (1965).

Not all observed weathering characteristics in Amboseli fall into the six stages given above. A few bones exhibited a striking pattern of mosaic surface flaking (Fig. 3) and others showed extensive flaking without significant cracking. The causes for the mosaic flaking and variability in cracking are not yet understood. Another type of unusual weathering was observed in an assemblage accumulated

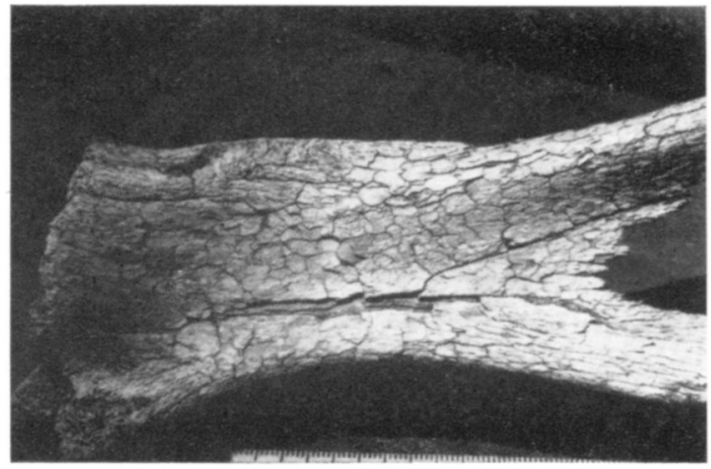

Figure 3. "Mosaic" pattern of bone surface cracking and flaking which is rare in the Amboseli assemblage compared to textures shown in Fig. 2. Cause of this weathering pattern is not yet understood.

by hyenas, within a shallow depression on a caliche "hard pan" surface. Many of the bones were chalky and had irregular small-scale flaking without extensive cracking. This weathering was not seen in the overall surface assemblage.

\section{Processes of Weathering}

Weathering is defined for the purposes of this paper as the process by which the original microscopic organic and inorganic components of a bone are separated from each other and destroyed by physical and chemical agents operating on the bone in situ, either on the surface or within the soil zone. Physical damage caused by carnivore mastication, trampling, fluvial transport, and geochemical changes which take place diagenetically during fossilization are excluded from consideration here, although such processes are closely related to weathering in its broader context.

Evidence for the important weathering processes in Amboseli is derived from observed variation in weathering characteristics in different macro- and micro-environmental contexts. At present, hypotheses concerning weathering processes are based on comparative data and inferences which have defined the potentially important variables but await empirical confirmation.

Variation in weathering stages on a single bone provides important evidence concerning process. In particular, bones in Amboseli are usually weathered more on upper (exposed) than lower (ground contact) surfaces. Bones with Stage 0 on the lower surface and Stage 
2 on the upper are not uncommon. Bones or parts of bones that project more than $10 \mathrm{~cm}$ above the ground surface are often less weathered than those close to the ground. Thus it seems that greatest bone weathering occurs in the zone immediately above the soil.

Recent work by Hare (1974; pers. comm.) indicates that organic breakdown in bones is enhanced by fluctuating temperature and humidity. Soil surfaces in open habitats can be subject to wide diurnal fluctuations in temperature and in moisture evaporating through the soil (Coe, pers. comm.; Ricklefs 1973). It is relatively easy to observe that such fluctuations occur in Amboseli; one can feel that bone surfaces are drier and hotter during midday than during morning or evening. The lower surfaces of bones are less subject to extremes in temperature and moisture than upper surfaces, and they can also be observed to weather relatively more slowly. Buried bones frequently show no sign of weathering even when exposed parts are in Stage 4 or 5. Thus, it seems reasonable to associate temperature and moisture fluctuations at the soil surface with bone weathering in Amboseli. Preliminary analysis of Amboseli bones of different weathering stages which indicates a correlation between the stages and progressive amino acid racemization in the collagen supports this interpretation (Hare, pers. comm.).

It seems probable that the physical stresses of repeated heating and cooling, and wetting and drying, contribute to the weathering characteristics in addition to microscopic changes in organic components. Large longitudinal cracks often appear on limb bones only a few days after the death of the animal. The relative importance of such physical stress may be affected by the original bone thickness and dersity and hence by the physical condition of the animal before death. This factor is of unknown significance in Amboseli, but it has been recently studied by Binford and Bertram (1977) in relation to bone fracturing and seems potentially important.

In some cases bones are more weathered on lower than upper surfaces. This usually occurs on highly alkaline soils where salts $\left(\mathrm{Na}_{2} \mathrm{CO}_{3}, \mathrm{NaCl}\right)$ crystallize on the bone surfaces (Fig. 4). The lower parts of the bones often are encrusted with salt crystals and show flaking and splitting caused by the force of crystallization. In situations where lower sur-

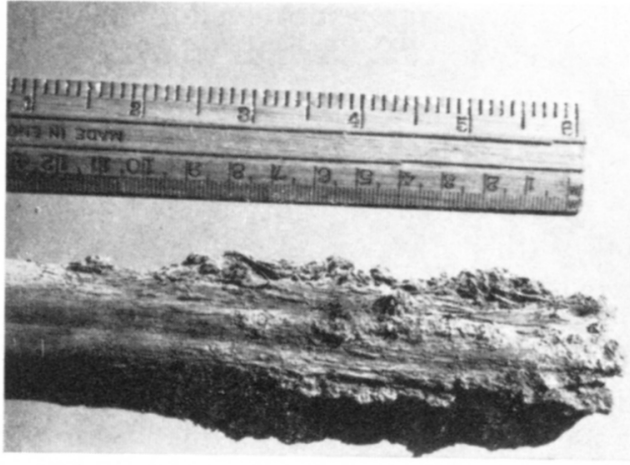

Figure 4. Bone surface cracking, splitting and fragmentation due to the precipitation of salts $\left(\mathrm{Na}_{2} \mathrm{CO}_{3}\right.$ and $\mathrm{NaCl}$ ) in pore spaces. Salts present in the soils and ground water precipitate as surface crusts during periods of net evaporation and may preferentially destroy those portions of a bone in direct contact with the ground.

faces are not in contact with salt-precipitating conditions, bacterial activity, roots or other organisms may be responsible for distinctive patterns of weathering. Dendritic patterns of shallow grooving observed on some Amboseli bones are interpreted as the result of dissolution by acids associated with the growth and decay of roots or fungus in direct contact with bone surfaces. Roots may also cause splitting and fragmentation of buried bones (Fig. 5). Termites have been found in bones obviously chewed by a small organism, and in some areas (particularly on red, non-alkaline soils north of the basin) presumed termite damage to bones is not uncommon (Fig. 6). Distinctive grooving known to be caused by larvae of the moth Tinea deperdella, which feed on the organic components of horns (Hill 1975; Behrensmeyer 1975), has been observed on many of the bovid horn cores in Amboseli (Fig. 7).

Another weathering process can produce distinctive polish on bone surfaces. Bone fragments swallowed by hyenas and either regurgitated or passed as fecal matter have a characteristic polished and "dissolved" appearance, often with sharply pointed ends. Bones can also acquire polish and edge rounding through continued trampling, as demonstrated by Brain (1967), and more work needs to be done in order to establish how to distinguish these two processes.

Overall, the major weathering effects in Amboseli appear to be caused by a combina- 


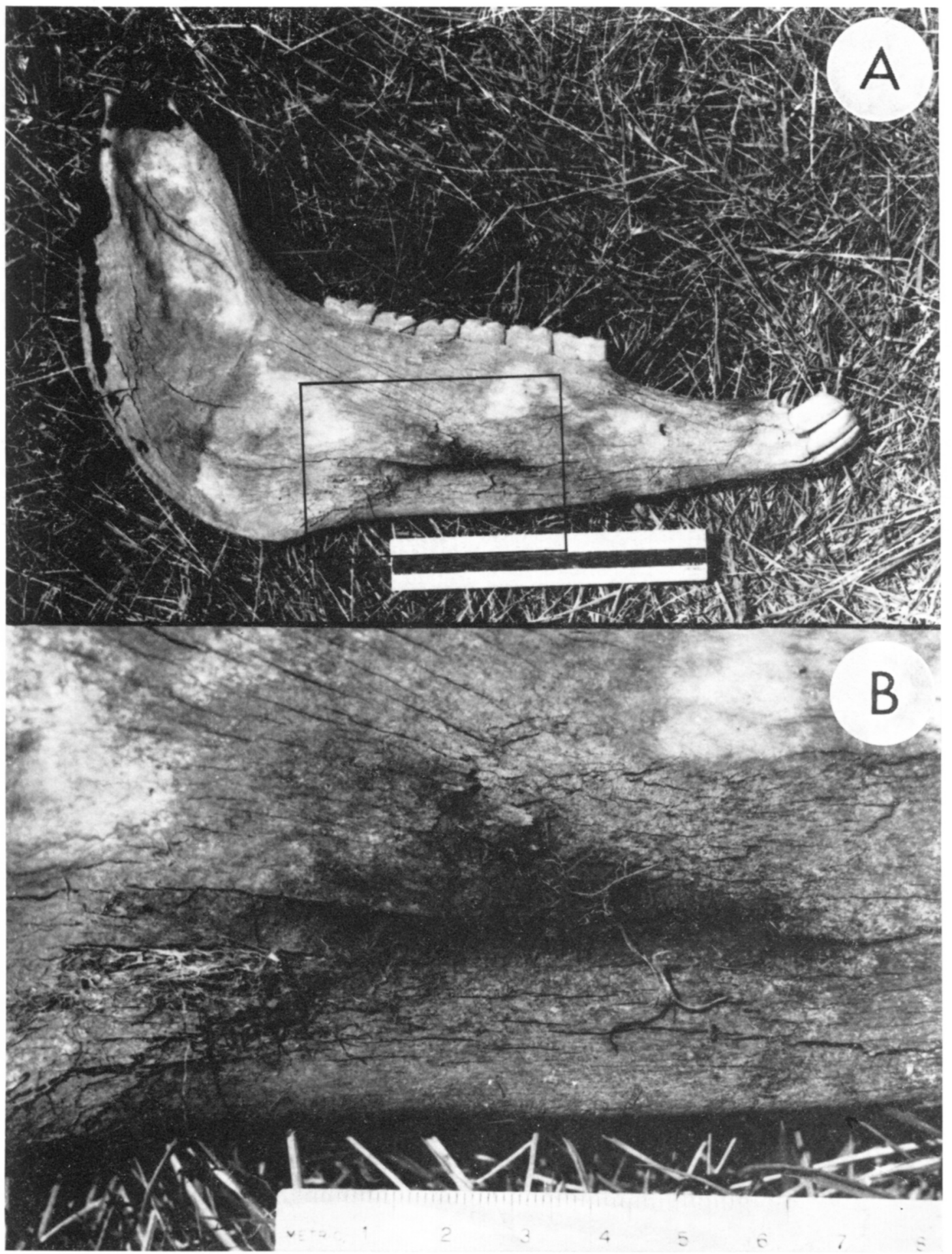

Figure 5. Cracking and expansion of a zebra (Equus burchelli) mandible due to root growth within the body of the ramus. Enlarged area in $5 \mathrm{~b}$ is designated in $5 \mathrm{a}$. 


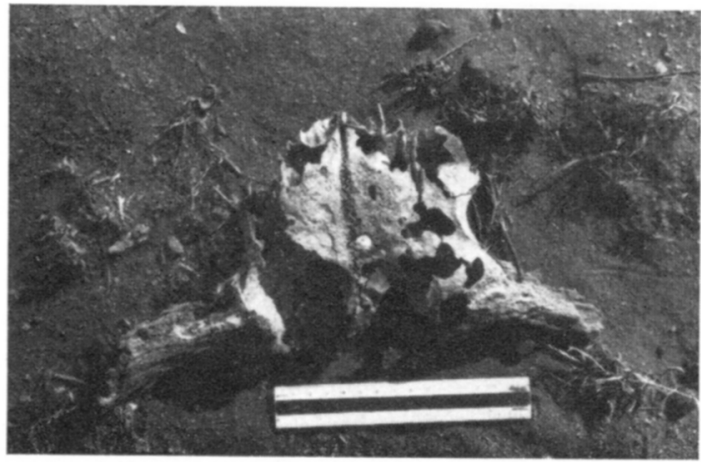

Figure 6. Cranium of cow showing perforations attributed to termites or possibly other unidentified insects. The bone was in a fragile state in 1975 and had fallen apart when relocated a year later.

tion of temperature and moisture fluctuations leading to bone decomposition at the ground surface. The weathering stages apparently are a result both of the intensity and duration of this process, and much local variation in weathering can be expected due to microclimatic conditions. In general, the less equable the immediate environment of the bone, the faster it should weather. Local variations in the patterns of weathering may occur due to soil chemistry, insects, and the effects of bone-collecting by hyenas. The relative importance of bacteria, root growth, and soil acids associated with plant decomposition cannot yet be assessed, except to note that the good condition of most buried bones argues against these as significant factors in bone destruction in Amboseli.

\section{Rates of Bone Weathering}

Weathering rates for Amboseli bones have been determined using 35 carcasses with known dates of death and one year or two successive years of observation. Results are pre-

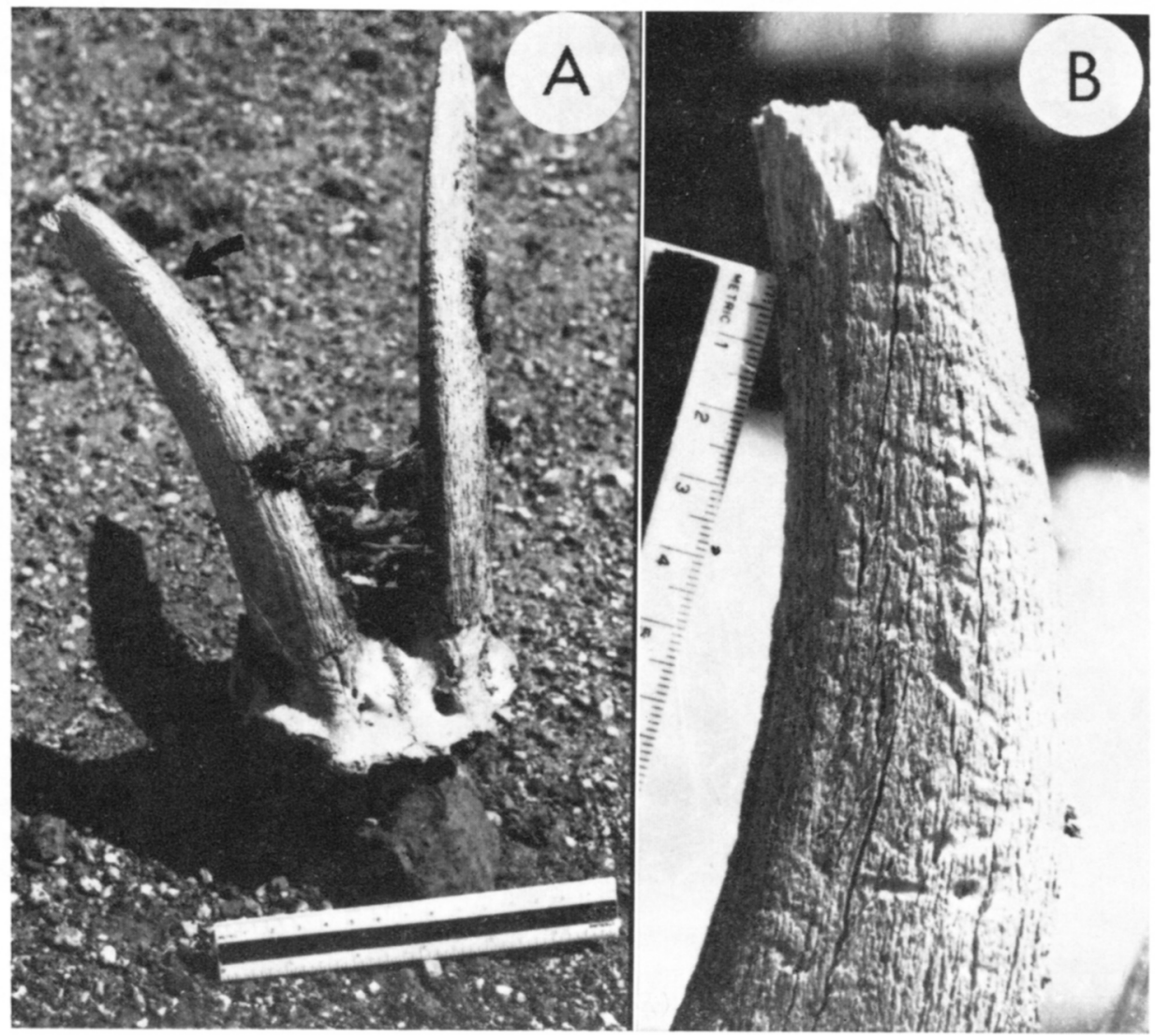

Figure 7. Grooving on horn cores of a male Grant's gazelle (Gazella granti) caused by larvae of the moth Tinea deperdella. Arrow in 7a indicates enlarged area in $7 \mathrm{~b}$. Bone fiber structure is vertical with grooving almost perpendicular to it. 
TABLE 1. Numbers of carcasses of known age since death that can be assigned to each weathering stage category. The total sample consists of 35 carcasses, 17 of which have been observed $2 \mathrm{yr}$ in succession for a total of 52 observations.

\begin{tabular}{cccccccc}
\hline \hline $\begin{array}{c}\text { Years since } \\
\text { death }\end{array}$ & \multicolumn{9}{c}{ Weathering stage } & $\begin{array}{c}\text { Total number } \\
\text { observations }\end{array}$ \\
\cline { 2 - 7 }$<1$ & 6 & 1 & 2 & 3 & 4 & 5 & 7 \\
$1-2$ & - & 7 & - & - & - & - & 7 \\
$2-3$ & - & 3 & 3 & - & - & - & - \\
$3-4$ & - & 1 & 5 & - & - & - & 6 \\
$4-5$ & - & - & - & 3 & - & - & 3 \\
$5-6$ & - & - & - & 3 & - & - & 3 \\
$6-7$ & - & - & 1 & 4 & 1 & 1 & 7 \\
$7-8$ & - & - & - & 3 & 3 & - & 6 \\
$8-9$ & - & - & - & - & 2 & - & 2 \\
$9-10$ & - & - & - & 1 & 1 & - & 2 \\
$10-15$ & - & - & - & 1 & 1 & 1 & 3 \\
& & & & & & & \\
\hline
\end{tabular}

sented in Tables 1 and 2 and Fig. 8. Information on dates of death has been provided by D. Western. Weathering stage determinations were done in 1975 and 1976.

Weathering stages appear to be predictably linked with time since death as shown in Fig.
TABLE 2. Weathering stages related to number of years since death for known-age carcasses in Amboseli.

\begin{tabular}{cc}
\hline \hline $\begin{array}{c}\text { Weathering } \\
\text { stage }\end{array}$ & $\begin{array}{c}\text { Possible range in } \\
\text { years since death }\end{array}$ \\
\hline 0 & $0-1$ \\
1 & $0-3$ \\
2 & $2-6$ \\
3 & $4-15+$ \\
4 & $6-15+$ \\
5 & $6-15+$ \\
\end{tabular}

8 , in spite of the variation in habitat and micro-environments represented by the carcass sample. Most bones falling into Stages 0, 1 and 2 have lain exposed for three years or less. Carcasses exposed longer than three years show a broad range of weathering stages, but none fall into Stage 1 or 0 . Thus it is possible to distinguish carcasses exposed for less than $3 \mathrm{yr}$ with fair certainty using weathering stages. Otherwise, the initial sample indicates that weathering stages are most useful in providing an estimate of minimum number of years since death (Table 2 ). With additional sampling and monitoring of the known weath-

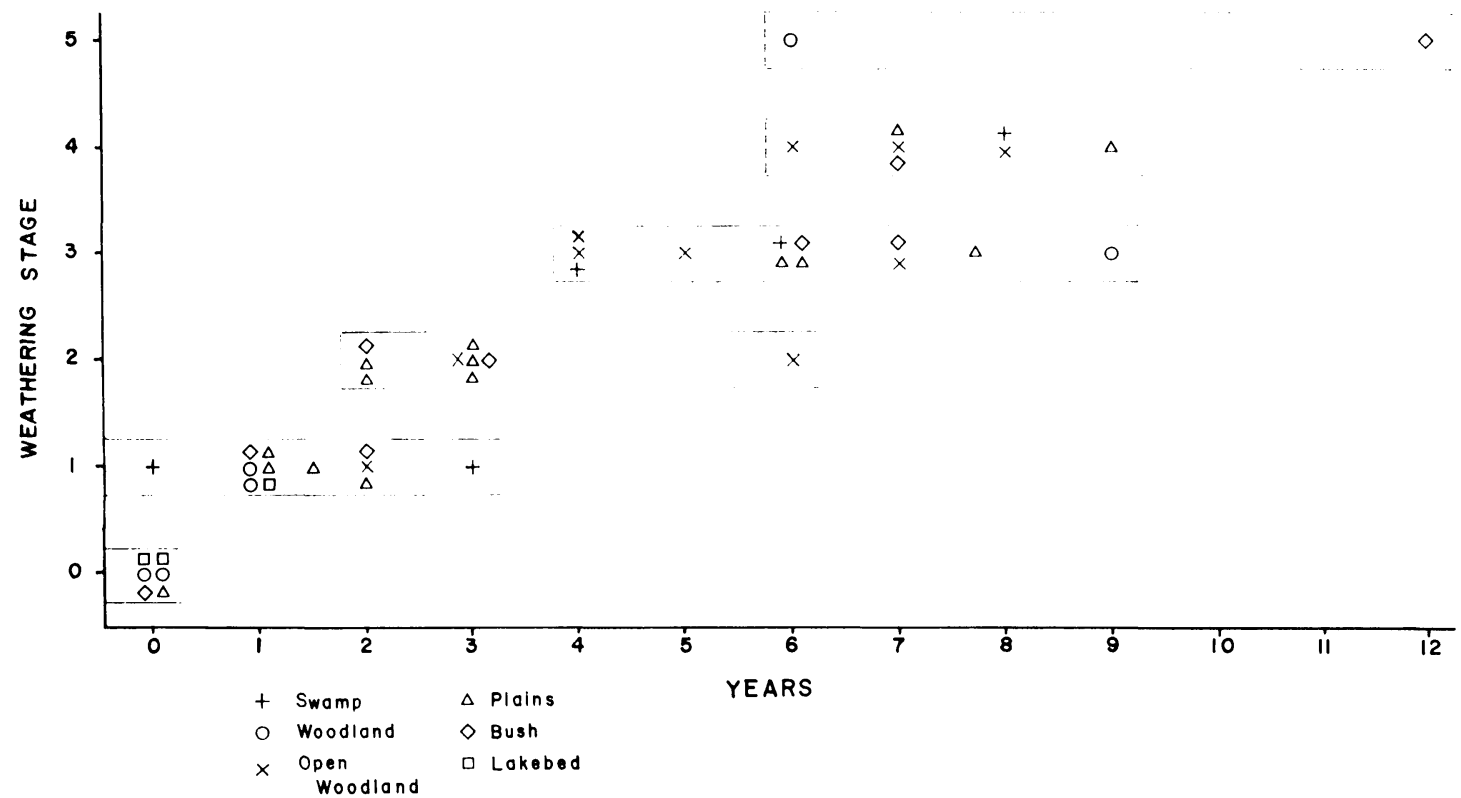

Figure 8. Weathering stage versus number of years since death for known-age carcasses in Amboseli. Each point represents a single weathering stage observation; in some cases the same carcass was observed in 2 successive years and thus appears twice on the graph. The total sample consists of 35 carcasses. Open-ended bars indicate that the maximum ages for the weathering stages are not yet known; minimum ages are more certain based on the present sample. 
ering-age of carcasses over several years, it should be possible to judge accurately the most probable number of years of exposure of any bone of a given weathering stage. This will be further refined by increased understanding of how weathering rates vary in different habitats and micro-habitats.

There is no consistent association between habitat and weathering stage revealed by the data presented in Fig. 8. This implies that localized conditions (e.g., vegetation, shade, moisture) are more important to bone weathering than overall characteristics of the habitats. However, the samples from each habitat are relatively small and may not reveal important trends. In the total bone sample, Stages $0-1$ are more common in the swamp habitat, and weathering in general seems to be slower where bones are kept moist and protected by swamp vegetation. As evidence of this, a rhinoceros (Diceros bicornis) killed in the swamp in 1961 was Stage 3 weathering in 1975, while a number of carcasses half its age were Stages 4 or 5 in other habitats.

In the total bone sample from Amboseli, 81\% of the recorded carcasses were Stage 0-3. Based on the information available at present, it seems safe to say that nearly all of these carcasses were exposed for $10 \mathrm{yr}$ or less. Sixty-two per cent of the total sample is Stage $0-2$, and this, for the most part, should represent the last five years of accumulation. Bones in Stages 3-5 may have been exposed for as much as $15 \mathrm{yr}$ but most are probably less than this. Thus, in Amboseli, bones exposed continuously on the surface show significant weathering by the time they are 3-5 yr old, and most disintegrate in less than $15 \mathrm{yr}$, although some may last longer under favorable micro-environmental conditions.

\section{Weathering Stages in an Attritional Bone Assemblage}

Overall the Amboseli bone sample is attritional, i.e., composed of carcasses added continually through death by predation, starvation, disease, etc. High mortality during drought periods among water dependent species adds a seasonal "mass death" component to the attritional assemblage which does affect its faunal composition (Behrensmeyer and Dechant, in prep.). Bones of animals dying during dry periods are subjected initially to

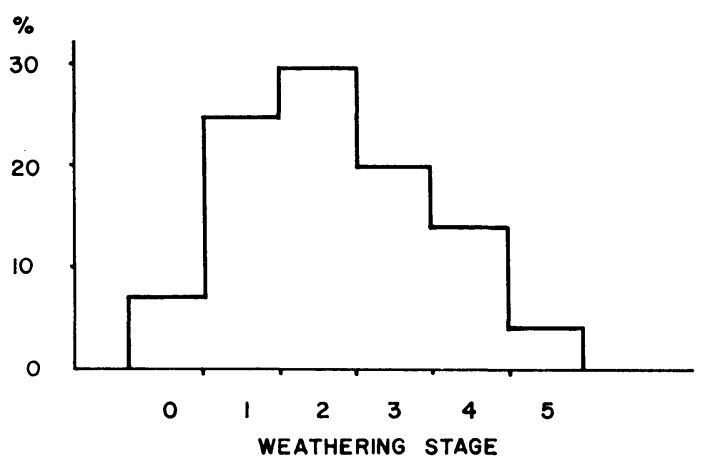

Figure 9. Percentages of carcasses (minimum numbers of individuals ) in each weathering stage for the total mammal sample (1534 carcasses). The peak in Stage 2 may be due to heavy drought mortality in 1972-1973, but it could also mean that bones remain in this stage for a longer period than in other stages.

intense desiccation unless protected within a mummified carcass. The potential effects of these initial conditions on subsequent weathering may be important but are unknown at present.

The relative numbers of carcasses in the six weathering stages are given in Fig. 9. Thirtyeight percent of the sample is "significantly weathered" (Stage 3-5), 55\% is "slightly weathered" (Stage 1-2) and only 7\% is "fresh" (Stage 0). Although how the Amboseli sample compares with other attritional surface assemblages is not yet known, it seems highly probable that these will all include some bones that are fresh, some that are slightly weathered and some that are weathered. This is significant in terms of the fossil record, since it provides a means of identifying an attritional assemblage.

Weathering has often been noted by paleontologists, usually as the cause of destruction of a valuable piece of morphological information on a specimen. However, in its weathering characteristics, the same specimen may hold important paleoecological data. Shipman (1977) has applied the weathering stage scheme given above to an excavated Miocene fauna from Ft. Ternan, Kenya. She notes that fossilization may obscure or change bone surface features, leading to difficulties in stage assignment.

In applying weathering stages to fossils, the worker must be sure that surface textures on bones are primary, and this limits the usable 

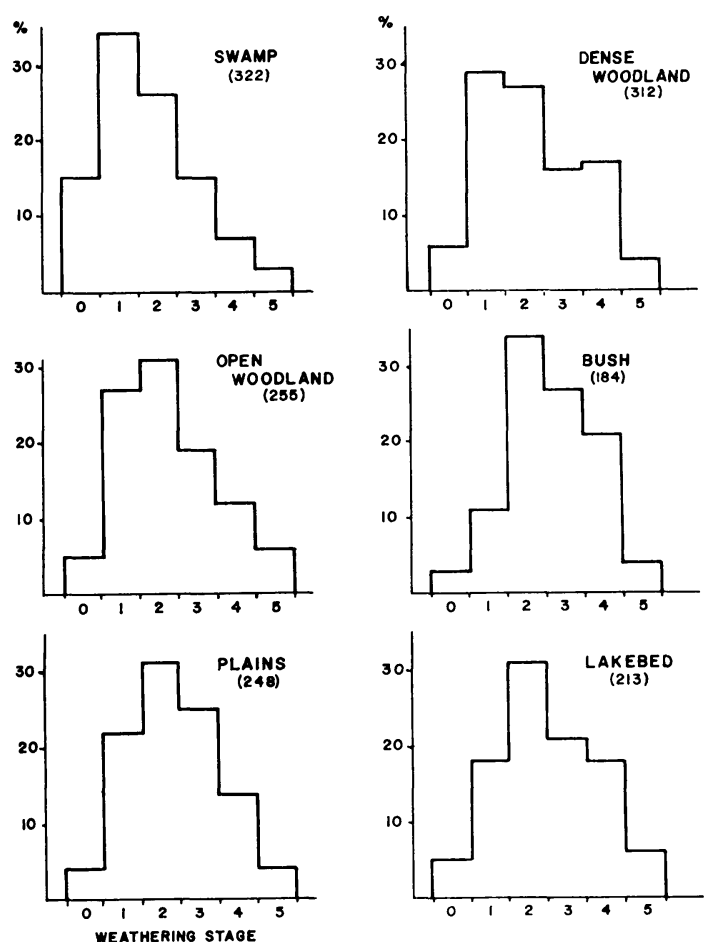

Figure 10. Percentages of carcasses in the six weathering stages for the major habitats in Amboseli. Numbers in parentheses are the total mammal sample for each habitat. Two $x$ two $\chi^{2}$ test on the numbers of carcasses in Stages 1 and 2 show that there is no significant difference $(P=.5-.75)$ between swamp and dense woodland but that for swamp vs. open woodland, $P=.90-.95$ and for swamp vs. bush, $P \gg .995$.

sample to carefully excavated bones or "float" specimens with matrix covering bone surfaces which have not been changed during recent erosion. Three broad categories: fresh (Stage $0)$, slightly weathered (Stage 1-2) and weathered (Stage 3-5) are most likely to be recognizable on fossils. Simple ratios of fresh to weathered bones may also provide important taphonomic evidence concerning the attritional or non-attritional nature of the original assemblage.

\section{Weathering Stages and Habitats}

The six major habitats in Amboseli: swamp, dense woodland, open woodland, plains, lakebed and bush, proved variable in the relative numbers of carcasses showing the different weathering stages (Fig. 10). This variation suggests what might be expected in an attritional fossil assemblage derived from different habitats. Two important factors may be responsible: 1) differential rates of weathering 2 ) changes in patterns of habitat utilization and/or mortality among the major herbivores over the last $10 \mathrm{yr}$.

Censuses of the living herbivores in the various habitats have been done by Western (1973 and pers. comm.) since 1967. During 1967-1969, the open woodland, plains and lakebed habitats were utilized heavily by the major wild herbivores, zebra and wildebeest. In 1973 these species increased their utilization of the dense woodland and swamp habitats during a drought period (D. Western pers. comm.). Bones from animals that died in 1967-69 should be Stage 2 and over, those from deaths in 1973 and later should be Stage 0-2. Assuming that weathering rates do not vary significantly from habitat to habitat, the areas used more heavily in 1967-69 should show a greater abundance of carcasses of Stage 2 and over. The data presented in Fig. 10 for lakebed and bush, in contrast to swamp, agree with this hypothesis. However, open woodland, plains and dense woodland do not fit as well, and it is apparent that other factors must be considered.

The more equable environments with respect to weathering processes are the swamp and dense woodland, where moisture and shade tend to moderate the diurnal and seasonal fluctuations in surface temperature and humidity. Slower weathering in these habitats could lead to relatively greater numbers of bones in Stage 0-1 than in other habitats, all other factors being equal. Such a weathering effect could be added to the changes in habitat utilization to give modes in Stage 1 for the swamp and dense woodland, but a Stage 2 mode in the others.

The biological and the taphonomic factors in the patterns of weathering stage distribution cannot be separated at present. However, habitat effects on bone weathering rates are being monitored, and once this factor is known it should be possible to isolate the ecological component in the weathering stage distributions. Surface bone assemblages could then become a source of information for the history of habitat utilization in modern vertebrate communities. 


\section{Weathering and Body Size}

There is evidence that bones of relatively small animals ( $\leqslant 100 \mathrm{~kg}$ ) weather more rapidly than those of large, thereby introducing a size-related bias into the Amboseli bone assemblage. Size-biasing is also caused by a variety of other processes which are discussed by Behrensmeyer and Dechant (in prep.). This paper deals with evidence relating weathering as previously defined to the preferential destruction of bones of small animals, including both small adults and juveniles of larger species.

Among the major herbivores, there are $15 \%$ fewer carcasses in Stage 3-5 for species smaller than $100 \mathrm{~kg}$, compared with larger forms. Populations have remained relatively stable in the basin, and the carcass input per year from all species has been more or less constant. Therefore all species should have proportional numbers of carcasses in each weathering stage unless there is variability in weathering rates. Effects of habitat should not be important because the smaller species are distributed over much the same areas as the large. It is possible that smaller bones do not always exhibit the typical characteristics of Stages $3-5$, or that they achieve them more slowly during weathering. The rate of decomposition may also be greater for smaller bones once they reach Stage 3, resulting in their more rapid elimination from the surface assemblage.

Bones of juvenile animals can be classified using the weathering stages, although it is clear that the immature bone varies from adult in weathering characteristics and in rates of decomposition. Bone of very young or foetal animals associated with bones of the mother usually were more weathered by one or two stages. Numbers of juvenile carcasses also vary with weathering stage. The ratio of juvenile to adult wildebeest (Connochaetes taurinus) is about .70 for the live population (Andere 1975). There is high juvenile mortality, but many carcasses are completely destroyed by carnivores. Those remaining should represent a constant proportion at each weathering stage unless: 1) weathering rates are different from those of adult bones, 2) mortality of juveniles versus adults has changed during the sample period, 3) carnivore consumption of juvenile versus adult carcasses has varied during the sample period. The ratio of juvenile to adult carcasses in Stage 0 is .50 , Stage 1: 3.7 , Stage 2: 1.0, Stage 3: .20. There were no juvenile wildebeest bones recorded in Stages 4 or 5 . Variations in ratios between Stages 0 and 3 may be caused by any one of the three factors given above, but it is difficult to explain the total absence of juvenile bones in Stages 4 and 5 unless weathering has decomposed them beyond recognition. The evidence thus indicates that immature bones weather more rapidly than adult. The record of juvenile mortality is lost for the bone sample older than $6-8 \mathrm{yr}$ in Amboseli.

It is not yet possible to separate the effects of the two variables, small size and immature bone structure, on weathering rates. Overall the latter appears to be more significant because there is a fairly large proportion of Stages 4 and 5 in the adult bone sample for species under $100 \mathrm{~kg}$, while these stages are almost unrepresented for juveniles. Monitoring of marked carcasses will eventually provide calibration for the size-related weathering effects.

\section{Weathering in Areas Other Than Amboseli}

A preliminary survey of known-age carcasses in Nairobi National Park suggests that the Amboseli weathering stages may be generally indicative of the number of years since death, even under different climatic and soil conditions. Seven carcasses of large mammals were all in Stage 2 after $2.5-3.0 \mathrm{yr}$ of weathering. This agrees well with the Amboseli data. A single carcass 4.5 yr old was Stage 3. Nairobi Park has a higher rainfall than Amboseli, cooler average temperatures due to its higher elevation and generally more vegetation. If weathering rates (at least through Stage 2 ) are partly independent of overall climatic regime, then weathering stages may be broadly applicable as an ecological tool. However, further sampling over a broad range of climatic regimes will be essential to establish this, and in temperate climates, the added effects of freezing and thawing will need to be tested.

A weathering rate experiment conducted by M. Posnansky and G. Isaac (Isaac 1967) at Olorgesailie, Kenya showed that after $7 \mathrm{yr}$ bones of a cow and juvenile goat had disintegrated to a cracked and friable state probably corresponding to Stage 3 or 5. Experiments 
and observations east of Lake Turkana, Kenya, indicate that bones go through stages similar to those in Amboseli, and that weathering rates are highly dependent on local conditions of moisture and vegetation cover (Hill 1975; Gifford, pers. comm.). Bones of a young topi (Damaliscus korrigum) placed on a roof several meters above the ground and fully exposed to sun and rain at Lake Turkana weathered to Stages 2 and 3 after 3 yr. This implies that conditions near the ground are not required to produce the recognizable weathering textures.

Observation of surface bone weathering in a variety of environments on several continents has shown that textural characteristics of the different stages are generally recognizable. This implies that structural features of the bones themselves have a major influence in the weathering characteristics regardless of external conditions. Temperature and humidity may exert strong control of the rate of this weathering, however.

\section{Potential Uses of Weathering in the Fossil Record}

Weathering features on fossils can provide evidence of taphonomic processes, and if primary weathering can be distinguished from transport abrasion and diagenetic effects, then primary weathering can give specific information concerning surface exposure of a bone prior to burial and the time period over which bones accumulated. Voorhies (1969; p. 31) has used the lack of variation in weathering as evidence that animals preserved in the Pliocene Verdigre Quarry died and were buried in a relative short period of time. If bones exhibit only a single weathering stage, this may indicate catastrophic death, but it could also mean that local conditions (e.g., moisture, rapid burial) inhibited weathering of gradually accumulating skeletal remains. An assemblage with bones in all stages of weathering may be attritional, representing long term accumulation over periods of years or tens of years. However, it could also reflect highly variable micro-environmental conditions in which some bones of the same carcass could remain in Stage 1 while others weathered more rapidly, even to the point of total distintegration. The relative importance of micro-environmental factors versus the length of time of accumulation can be sorted out using: 1) the spatial distributions of bones of different weathering stages, 2) the variation in weathering on bones of a single animal, 3) the relationship of weathering stages to different sedimentary environments. If bones in all weathering stages are homogeneously mixed in a single deposit, then it is highly likely that they represent attritional accumulation. On the other hand, if bones of the same weathering stage are clustered together, then they may reflect local variation in weathering conditions and may or may not be attritional. Careful study of fossil remains in situ will obviously be important in establishing the history of accumulation and surface exposure of any particular vertebrate assemblage, and further study of modern land surfaces may reveal other helpful lines of evidence.

In archeological sites, weathering could provide important evidence for relative duration of occupation, recurring occupations, or the presence of a "background" of skeletal material that was not related to site formation. Recent ethnoarcheological investigation of modern campsites has shown that much bone refuse may be buried by trampling and remain in Stage 0-1 (D. Gifford, pers. comm.; Gifford and Behrensmeyer, 1977). If bones were present on the site prior to occupation, they could be similarly buried but should represent a wide range of weathering categories, unlike the cultural refuse of a short-term occupation. The potential use of weathering in an archeological context seems promising, but systematic investigations using information from recent bones have yet to be done.

\section{Conclusion}

Bone weathering is a potentially useful tool in paleoecology, archeology and recent ecology. The presence of a wide range of weathering stages in bones from a single deposit may indicate that it is an attritional assemblage. This can strongly affect paleoecologic interpretations concerning the faunal composition, relative abundances of taxa and age-structure of the preserved populations because it indicates that taphonomic biases inherent in an attritional bone assemblage must be taken into consideration. The presence of a single weathering stage or a mixture of various stages on an archeological site can indicate important differences in duration of occupation, local conditions of burial and/or the presence of 
non-cultural bone material. Bone weathering rates, when known for a variety of environmental conditions, should provide ecologists with a means of censusing animals and surveying habitat utilization over periods of perhaps $1-15+$ yr.

Work on bone weathering has only begun, and readers are advised to treat statements in this paper as hypotheses which need testing through additional research on both recent and fossil bones. The major point of emphasis is that weathering characteristics do record meaningful information which deserves to be recognized and investigated further. The weathering stages given in this paper may well need elaboration and revision as more work is done. They should be considered provisional, but hopefully will help to establish a useful basis of communication and promote interest in weathering rates and processes.

\section{Acknowledgments}

Information and assistance of major importance to the study of bone weathering in Amboseli was generously given by Dorothy $\mathrm{E}$. Dechant, Elizabeth Oswald and David Western. Permission to work in Amboseli National Park was granted by Dr. Perez Olindo, then Director of National Parks, and Mr. E. K. Ruchiami of the Office of the President of Kenya. Their cooperation, and also that of Mr. Joe Kioko, Park Warden, was much appreciated. The staff of the National Museum of Kenya were very helpful in providing osteological material for the study. Chris and Alison Hillman contributed information and help in aging carcasses in Nairobi National Park. I also thank Diane Gifford, I. Findlater, E. P. Hare, Andrew Hill, G. Isaac, and Judith Van Couvering for their contributions, ideas and stimulating skepticism regarding bone weathering.

The study of recent bones in Amboseli Park was supported primarily by the National Geographic Society (Grant \#1508), with additional funding provided by National Science Foundation Grant \#GS 268607A-1.

\section{Literature Cited}

Behrensmeyer, A. K. 1975. The Taphonomy and paleoecology of Plio-Pleistocene vertebrate assemblages of Lake Rudolf, Kenya. Bull. Mus. Comp. Zool. 146:473-578.

Behrensmeyer, A. K. and D. E. Dechant. In prep. The recent bones of Amboseli Park, Kenya in relation to East African Paleoecology. To be in: Behrensmeyer, A. K. and A. Hill, eds. Fossils in the Making. In Prep. (Wenner-Gren Foundation for Anthropological research symposium 69.)

Binford, L. R. AND J. B. Bertram. 1977. Bone frequencies-and attritional processes. Pp. 77-153. In: Binford, L. R., ed. For Theory Building in Archeology. Academic Press; New York.

Brain, C. K. 1967. Bone weathering and the problem of bone pseudotools. South Afr. J. Sci. 63(3): 97-99.

Gifford, D. P. AND A. K. Behrensmeyer. 1977. Observed formation and burial of a recent human occupation site in Kenya. Quaternary Res. 8:245266.

HARE, E. P. 1974. Amino acid dating of bone-the influence of water. Carnegie Inst. of Washington Year Book. 73:576-581.

Hill, A. 1975. Taphonomy of contemporary and late Cenozoic East African vertebrates. $331 \mathrm{pp}$. Unpubl. Ph.D. thesis; Univ. of London, London.

IsAAC, G. I. 1967. Towards the interpretation of occupation debris: some experiments and observations. The Kroeber Anthropol. Soc. Pap. 37: 31-57.

Rickleffs, R. E. 1973. Ecology 861 pp. Chiron Press; Portland, Oregon.

Shipman, P. 1977. Paleoecology, taphonomic history, and population dynamics of the vertebrate fossil assemblage from middle Miocene deposits exposed at Fort Ternan, Kenya. Unpubl. Ph.D. thesis; New York Univ. (Anthropology), New York.

Tappen, N. C. And G. R. Peske. 1970. Weathering cracks and split-line patterns in archeological bone. Am. Antiq. 35:383-386.

Toots, H. 1965. Sequence of disarticulation in mammalian skeletons. Contrib. Geol. 4:37-39.

Voorhies, M. 1969. Taphonomy and population dynamics of an early Pliocene vertebrate fauna, Knox County, Nebraska. 69 pp. Contrib. Geol., Spec. Pap. No. 1. Univ. Wyo. Press; Laramie, Wyoming.

Western, D. 1973. The structure, dynamics and changes of the Amboseli ecosystem. 385 pp. Unpubl. Ph.D. thesis; Univ. of Nairobi (Zoology), Nairobi.

Western, D. and C. van Praet. 1973. Cyclical changes in the habitat and climate of an East African ecosystem. Nature. 241:104-106. 